Article

\title{
Developing Competencies in a Mechanism Course Using a Project-Based Learning Methodology in a Multidisciplinary Environment
}

\author{
Alejandro Guajardo-Cuéllar*(D), Carlos Renato Vázquez (D) and Manuel Navarro Gutiérrez (D)
}

Citation: Guajardo-Cuéllar, A.; Vázquez, C.R.; Navarro Gutiérrez, M. Developing Competencies in a Mechanism Course Using a Project-Based Learning Methodology in a Multidisciplinary Environment. Educ. Sci. 2022, 12, 160. https:// doi.org/10.3390/educsci12030160

Academic Editor: Ronan Dunbar

Received: 18 January 2022

Accepted: 13 February 2022

Published: 25 February 2022

Publisher's Note: MDPI stays neutral with regard to jurisdictional claims in published maps and institutional affiliations.

Copyright: (C) 2022 by the authors. Licensee MDPI, Basel, Switzerland. This article is an open access article distributed under the terms and conditions of the Creative Commons Attribution (CC BY) license (https:// creativecommons.org/licenses/by/ $4.0 /)$.
Escuela de Ingenieria y Ciencias, Tecnologico de Monterrey, Zapopan 45138, Mexico; cr.vazquez@tec.mx (C.R.V.); manuel.navarro.gtz@tec.mx (M.N.G.)

* Correspondence: alejandro.guajardo@tec.mx

\begin{abstract}
Design of Mechanism is a standard subject in Mechatronics and Mechanical Engineering majors. Different methods and tools are used by lecturers to teach the subject. In this work, we investigate the impact on the competencies development by implementing a project-based learning methodology in a mechanism course. For this, we analyze the performance of students from two different groups. The first group is taught in a traditional fashion developing a final project just related to the discipline, and the second group is taught in a multidisciplinary context where the final goal is to develop a complex project where the mechanisms subject is one complementary subject with the others. The development of engineering competencies, declared for this course, is presented for both groups through the evaluation of different aspects; also, a survey of satisfaction from the students of both groups is presented. Overall, the results show that the multidisciplinary project-based learning method, having a nonacademic training partner as sponsor and solving a real nonacademic project, improves the development of competencies related to practical applications and increases the motivation and appreciation of the student towards the mechanism learning discipline.
\end{abstract}

Keywords: mechanisms; project-based learning PBL; multidisciplinary project; competency development; educational innovation; higher education

\section{Introduction}

Mechanism analysis and simulation is a core course taught to Mechatronics Engineering and Mechanical Engineering students. Typically, the course is taught to sophomores and juniors. In general, the prerequisites are freshman math, rigid body mechanics, and CAD tools. Traditionally, the course addresses the analysis of rigid body dynamics applied to bar mechanisms and methodologies for mechanisms synthesis. For many students, this is the first course where the link between theoretical content and a real application is observed. The importance of this course is closely related with the ability of the student to design solutions for machines, robots, and automation processes. Despite the fact that the course mainly focuses on theoretical concepts and fundamentals, students are expected to develop the skills to apply the learned methodologies, i.e., the students must develop a competency to design solutions for relevant problems that involve moving parts. Developing this competency in a course with a theoretical nature, due to the learning contents of the course, represents a huge challenge. Unfortunately, traditional approaches to lecture mechanisms frequently dismiss the practical part, focusing on the theoretical content.

Many authors have documented best practices to teach a mechanisms course. Ceccarelli [1] discussed a historical evolution of teaching mechanisms theory. He documented the developments in teaching the discipline prior to the 21st century. Two trends are found in the literature related to teaching mechanisms: the application of technological tools and the introduction of new learning techniques and pedagogy. Most of the works on this topic analyze the improvement in learning and motivation by using computational 
and technological tools for the dynamic and kinetic analysis of mechanisms. Previous works related to the use of software are found by several authors ([2-18]). All these authors reported several novel techniques to improve the teaching of mechanisms with the aid of computational tools such as programming languages, graphic units interfaces, CAD software, virtual and remote labs, and applications for mobile devices. Nevertheless, in this work is reported the pedagogical findings in the learning process by implementing project-based learning for mechanisms teaching with two different control groups using different methodologies.

Regarding the introduction of pedagogical methods to enhance the learning process in the mechanisms study, García-Alonso et al. [19] reported the success of teaching mechanisms content in projects through service-learning. They reported the impact and the increase in motivation within the students to learn the discipline in the context of a real-world problem; however, they do not report a comparison of the competencies development in this environment versus a traditional project-based learning (PBL) methodology with an academic project as studied here. Duma et al. [20] discussed the impact of a mechanism course in a research environment; they fitted the learning of mechanism in a multidisciplinary research group that focus in optomechatronics. They conclude that a research area such as optomechatronics can fit several courses for electrical and mechanical engineers, mechanisms being of great relevance. An interesting approach to teach mechanisms was presented by Fernández del Rincón et al. [21]. In this work, they documented how students have better understanding of mechanisms when they are challenged through an internal competition with a relevant problem to solve. These previous investigations linked different pedagogical methods with teaching mechanisms. Overall, most authors reported how to teach mechanisms using PBL [22]. PBL is a pedagogical method widely reported in the literature ([23-28]). The PBL methodology is used in many disciplines in all learning levels, from basic education to higher level education around the world ([29-32]). As described before, teaching mechanisms have not been excluded from this method. Many authors proposed enhancing techniques to learn mechanisms through PBL. However, the main contribution in this work is comparing PBL with different context and motivation of the project proposed. Our interests focus on the application of PBL to develop skills required to design mechanisms. Here is compared the learning experience of the students under PBL in a multidisciplinary project vs. a traditional learning approach. In addition, the project proposed to be developed with the aid of different mechatronic engineering disciplines is proposed by an external organization. The traditional approach uses PBL in an academic project that is developed in a traditional course environment.

In order to address the challenge of linking theoretical studies with the solution of real problems that involve several relevant engineering disciplines such as mechanisms, the Tecnologico de Monterrey, a higher education institution in Mexico, has moved its educational model towards a competency development model, named Tec21 [33,34], by adopting PBL as the central pedagogy. This effort lies in the trend that modern educational institutions have adopted in their educational models, moving from objective-based learning [35] to competency development ([36-40]), in which students develop skills to fill the gap between theory and application in actual problems. In order to have a smooth transition to the Tec21 model, Tecnologico de Monterrey implemented the Semestre $i$ strategy during the last years, which is translated to English as Term i. Semestre $i$ is a full term that combines four to six different traditional courses related to a challenge that must be solved during the term; here, the challenge is sponsored by an external institution, and during the term the competencies to be developed are well defined. For this, students receive lectures, but the final grade is the result of the integration of the discipline with a multidisciplinary complex project, involving all the courses in the term.

In this paper, we describe the learning observed during the application of a Semestre $i$ based on PBL; in particular, we focus on the knowledge and skills developed in a course of analysis and simulation of mechanisms. The comparison of this methodology with a traditional course with no multidisciplinary context is the main interest of this investigation. This 
comparison allow us to identify the improvements in the learning process, evaluating competencies development and theoretical content learning, paying special attention to competencies related to the application of theoretical content in real problems. Furthermore, we also compare the students' appreciation of the course.

This paper is organized as follows. First, the article explains the mechanism course delivered in the Semestre i format in Section 2.1, and the traditional format in Section 2.2. Next, the details of both methodologies used in the two different groups, the activities, and tasks in the groups are explained in Section 2.3. After this, the results obtained in the performance of the two groups and the reception of the methodology by the groups is presented and discussed in Section 3. Finally, recommendations and conclusions from the study are given.

\section{Materials and Methods}

\subsection{Mechanism Course: Semestre I Format}

Semestre i is a problem-based learning initiative at Tecnologico de Monterrey in which a group of students of the same program and term focuses on solving a real-world challenge. For this, regular courses are redesigned as learning modules that contribute with the theoretical background and skills required to propose a solution to the challenge. The challenge is designed by the team of professors and an external institution (frequently a company, referenced as trainer partner), based on the competencies that students must develop during the term in course.

In particular, in this work we report the experience of a Semestre i entitled MR WAS (mobile robot for a warehouse automated system), in which students from the Mechatronics Engineering program, taking its fifth term, must design and develop a prototype of an autonomous guided vehicle (AGV). The trainer partner is a company that integrates industrial automation technology, being interested in exploring AGV technology for its use in electronic-manufacturing companies settled in the city. As a result, several requirements are established for the robot development, including restrictions on materials, battery autonomy, dimensions, speed, ground slope, load dimension and weight, functional modes, etc.

In this Semestre i, six courses are taken by students: Technology of Materials, Actuators, Analysis and Simulation of Mechanisms, Basic Electronics, Microcontrollers, and Administration and Evaluation of Projects. During 11 weeks, the students attend sessions of the corresponding courses (modules) in which the professors deliver theoretical concepts and techniques, as in traditional courses. During the same period, students spend 2 or $3 \mathrm{~h}$ daily to work on their projects development. There are 3 weeks, distributed along the term, in which students completely focus on the project; these are named immersion weeks. At the end of each immersion week, students must present and report their progress; there are mandatory milestones for each immersion week. Projects are developed in teams of $4-5$ students; however, several tasks must be developed and reported on individually, in order to verify the competencies development.

Table 1 describes the modules associated with each competency. For instance, the course of Analysis and Simulation of Mechanisms is involved in the competencies 1.2, 3.1, and 4. In order to evaluate competency 1.2, each student must design and manufacture a prototype of a four-bar mechanism that has the purpose to elevate a load of certain dimensions, being actuated by a standard electrical actuator. Similarly, for competency 3.1, each student must provide a standardized manufacturing draw of a mechanical component of the prototype to be manufactured, and a 3D assembly CAD file showing a sub-system of the designed AGV. At the end of the third immersion week, the students must exhibit their AGV prototype in a formal presentation with the presence of the trainer partner engineers. Competency 4 is evaluated in this event, during the exposition and through direct questions to each student. 
Table 1. Competencies vs. Courses. The mark + indicates the competencies associated with each course. C1: Materials, C2: Mechanisms, C3: Actuators, C4: Microcontrollers, C5: Electronics, C6: Projects.

\begin{tabular}{|c|c|c|c|c|c|c|c|}
\hline & & $\mathrm{C} 1$ & $\mathrm{C} 2$ & C3 & C4 & C5 & $\overline{\mathrm{C} 6}$ \\
\hline $\begin{array}{c}\text { The } \\
\text { student }\end{array}$ & $\begin{array}{l}\text { (1.1) Selects materials } \\
\text { for a mechatronic device } \\
\text { according to functional and } \\
\text { sustainable requirements. } \\
\text { (1.2) Designs and prototypes } \\
\text { mechanisms that fulfill } \\
\text { functional requirements. } \\
\text { (1.3) Integrates electromechanical } \\
\text { and electronic devices } \\
\text { considering performance requirements. } \\
\text { (3.1) Describes and documents } \\
\text { specifications of a mechanical } \\
\text { system by using a CAD tool. } \\
\text { (3.2) Designs and implements } \\
\text { code in an embedded system } \\
\text { integrating peripherals } \\
\text { in accordance to engineering } \\
\text { specifications. } \\
\text { (3.3) Manages projects to } \\
\text { fulfill design and } \\
\text { time requirement by } \\
\text { using standard methodologies } \\
\text { and technological tools. } \\
\text { (4) Proposes and evaluates } \\
\text { different solutions } \\
\text { to an identified } \\
\text { problem according to the } \\
\text { established requirements. }\end{array}$ & + & + & + & + & + & + \\
\hline
\end{tabular}

Professors are responsible for the evaluation of their corresponding modules, related competencies, and the project progress regarding their expertise areas. Different technical aspects of the project are evaluated at the end of each immersion week and at the final presentation. Professors also provide technical consulting and methodological guidance to students to accomplish their projects. In particular, professors of the materials and mechanisms modules advise students, perform continuous revisions, and provide feedback regarding all the mechanical aspects of the student's prototypes. Similarly, professors of the actuators, electronics, and microprocessors modules advise students regarding all the electrical and electronic aspects.

\subsection{Mechanism Course: Regular Format}

The course of Analysis and Simulation of Mechanism has a long tradition in engineering schools. Modern mechanisms courses still focus on well-established topics, such as graphical synthesis, kinematic analysis of bar mechanisms, etc. The main goal of the course is to provide theoretical tools to perform analysis of planar mechanisms and to synthesize (determine the topology and main dimensions) four-bar planar mechanisms. Accordingly, the mechanisms course at our campus is based on the following syllabus:

Analysis and Simulation of Mechanisms

1. Introduction to mechanisms.

1.1 Preliminaries: definition of mechanism, classification of links and joints.

1.2 Degrees of freedom: Gruebler equation.

1.3 Grashoff condition. 
1.4 Classical mechanisms, isomers, inversions.

2. Synthesis of mechanisms.

2.1 Graphical synthesis of four-bar mechanisms for two and three positions.

2.2 Analytical synthesis of four-bar mechanisms for two positions.

2.3 Synthesis of bar mechanisms based on CAD tools.

2.4 Practical considerations on mechanism design and manufacture.

3. Analysis of mechanisms.

3.1 Analysis of four-bar mechanisms: position, velocity, acceleration.

3.2 Methods for kinetic analysis of four-bar mechanisms.

3.3 Analysis on CAD tools.

The course is delivered in two different formats: as part of Semestre $\mathrm{i}$ (for students of the Mechatronics Eng. program) or as a regular course (for students of the Mechanical Eng. program). The content is the same in both cases, mainly based on the well-known book of R.L. Norton ([41]). Topics 2.3, 2.4 and 3.3 are added to help students in their projects. In particular, topic 2.3 provides a methodology for the efficient synthesis of mechanisms based on the CAD tool SolidWorks. Topic 2.4 incorporates content that helps students to manufacture a mechanism, such as practical designs of links and joints and manufacture methods that can be performed by students at the campus. Topic 3.3 provides software tools to perform fast analysis of their designed mechanisms, such as determining the force/torque of the actuator that will drive the mechanism. In detail, students implement code in MatLab to compute position, velocity, acceleration, and torque in four-bar mechanisms; similarly, they simulate mechanisms in SolidWorks, using the complement Motion Studio that performs multi-body dynamic simulations.

The first module, Introduction to Mechanisms, is evaluated by an open-question exam. The second module, Synthesis of Mechanisms, is evaluated by exercises in which the student has to design four-bar mechanisms for two given problems. The third module, Analysis of Mechanisms, is evaluated by an exercise in which the student must compute positions, velocities, accelerations, and forces/torque of a crank-slider mechanism, based on a MatLab code implemented by the student.

Moreover, in the regular course format, students must develop a project in which they have to design and manufacture a prototype of a mechanism according to established requirements (frequently, the mechanism is required to move a load of certain dimension and weight between two extreme positions). The mechanism must be manufactured in either steel or aluminum. The project must be developed in teams of 2-3 students. Additional to the prototype, students are required to deliver a report including diagrams of the designed mechanism, position and (static) force analysis, manufacturing drawings of all the mechanical components of the prototype, 3D assembly in CAD, and a full list of materials and components. In Semetre i, students must deliver a similar report.

The main difference between the Semestre $i$ and the regular course formats of the mechanisms course is the project. Table 2 summarizes the relevant aspects of the project in both course formats. The difference in the project requirements is due to the nature of the projects' proposals and development. In Semestre i, the project is proposed by the team of professors and the trainer partner in accordance with real-world restrictions; moreover, even if the project is a prototype, the trainer partner expects certain quality and manufacturability features. On the other hand, in a regular course, the projects are proposed by the students; thus, they have to establish the requirements according to the addressed problem. Furthermore, in Semestre i, students focus only on one project; on the contrary, in a regular course, students must develop a different project for each subject attended during the term. 
Table 2. Comparison of project requirements in the mechanisms course for both delivery formats:

Semestre i and regular course.

\begin{tabular}{lll}
\hline & Semestre i & Regular Course \\
\hline Project purpose & $\begin{array}{l}\text { Central asset in the problem-based learning strategy to } \\
\text { develop competencies }\end{array}$ & Activity for the application of theoretical content \\
\hline Project definition & Defined by Semestre i designers: lift mechanism & Proposed by students (four-bar mechanism) \\
\hline Movement and load requirements & $\begin{array}{l}\text { Defined by Semestre i designers: lift a box of } 20 \mathrm{~cm} \times \\
20 \mathrm{~cm} \times 15 \mathrm{~cm} \text { and } 8 \mathrm{~kg} \text { at } 80 \mathrm{~cm} \text { from floor }\end{array}$ & Proposed by students according to selected project \\
\hline Actuation & $\begin{array}{l}\text { Defined by Semestre i designers: commercial linear actua- } \\
\text { tor to be selected and bought by students }\end{array}$ & Manually driven \\
\hline Materials & To be selected by students according to a methodology & Steel or aluminum \\
\hline Dimensions of the assembly & Dimensions of the AGV defined by general requirements & No restriction \\
\hline Manufacturing quality & $\begin{array}{l}\text { Specific directions: superficial finishing, rivets are not } \\
\text { allowed, welding properly performed, no bending or de- } \\
\text { formation of links, no clearance at joints, joint-design } \\
\text { guidelines to avoid link movements outside the plane, etc. }\end{array}$ & $\begin{array}{l}\text { General directions: no deformation of links, } \\
\text { avoid clearance at joints. }\end{array}$ \\
\hline Operation at final presentation & $\begin{array}{l}\text { Operation under free and load conditions along the complete } \\
\text { trajectory, being driven by the actuator, no vibration must be } \\
\text { perceived, no mechanism seizure, smooth movement }\end{array}$ & $\begin{array}{l}\text { Manual operation to fulfill the requirements } \\
\text { established by students }\end{array}$ \\
\hline
\end{tabular}

\subsection{Study Case: Semestre I vs. Regular}

In this work, we compare the results of two groups of students attending the Analysis and Simulation of mechanisms course in both formats: Semestre $i$ and Regular course. The goal of this comparison is to evaluate the learning improvement of the Semestre i format with respect to a regular course format. Another aspect of interest is the appreciation, of students, of the course and the Professor's performance under the Semestre i format.

The first group involves 30 students of the fifth term of the Mechatronics Eng. program, attending the course as part of Semestre i. The second group involves 38 students of fifth and sixth term of the Mechanical Eng. program, attending the subject in the regular course format. The sample size of the experiment contains all the elements of the university within the campus where the experiment was conducted, i.e., all the students of both majors of the sixth semester were part of the sample. The selection of which program is going to take Semestre $i$ and Regular course is beyond the design of the educational experiment. It completely depends on the university administration. This selection on which students complete Semestre i or Regular course does not allow to select specific population groups such as gender, background, or race. The only difference between the two experimental groups is the major. However, the two groups are equivalent for the matter of this investigation; both groups belong to the same semester of their major, and both groups had already taken the same prerequisite required for a mechanisms course. For both majors, mechanisms is a core discipline in their curricula. During the period, students from one group did not have contact with students of the other group. Both courses were delivered during the same period, by the same Professor. The delivered contents were the same, as described in the syllabus of Section 2.2. Similarly, the evaluation of the theoretical content was identical in both groups, i.e., the same exam was applied to both groups and the same exercises about synthesis and analysis were assigned to both groups. Similarly, in both courses, students were asked to perform the same activities to evaluate competencies 1.2 and 3.1 of Table 1.

The only difference in the groups consisted of the project as described in Table 2, and its evaluation (the project evaluation in Semestre $i$ is performed by the team of professors according to a set of aspects involving all the subjects). Nevertheless, for comparison purposes, the final projects (prototype and final report) of both groups were also evaluated by a team of three professors of the Mechanical and Mechatronics Department by considering the same aspects: 
1. The mechanism fulfills the movement and load requirements.

2. Materials used in the prototype are suitable for the application.

3. A correct position analysis is reported.

4. A correct force/torque (static) analysis is reported.

5. Quality of the manufactured components.

6. Quality of the assembly (perceived during mechanism operation).

7. Difficulty level (detailed design and manufacturing).

The first four aspects were graded with a binary scale: 0 -Not satisfactory, 10 - Satisfactory. Aspects 5 and 6 were graded with the following scale: 0 -Not observed or poor quality, 5-Fulfills minimum functionality requirements but the design and construction is not robust and might present failure, 10-Fulfills proper functionality and the design and construction is robust. Aspect 7 was graded with the following scale: 0 - Few components were designed and fabricated, 5-Adequate design but some components were not fabricated for a complete functionality, 10-Complete design and fabrication of all the required components for a good performance.

In order to improve the quality of the courses at Tecnologico de Monterrey, at the end of the term students are required to answer a questionnaire about their personal appreciation of each one of the courses attended during the period. The responses to this questionnaire provide a rough insight of the appreciation of the students about both the course and the Professor's performance. The common questions are as follows:

1. Usefulness and relevance of the course contents.

2. Appropriate level of intellectual challenge during the course.

3. Clarity and coherence of the evaluation scheme.

4. Quality of the interaction with the Professor.

5. Performance of the Professor as a learning guider.

6. Would you recommend another student to take this course with this Professor?

Questions 1-3 are related to the course design. Question 1 is strongly related to the project development, in which students must apply course contents to design and manufacture their mechanisms. The answer to Question 2 can also be affected by the project development, whether the students experience difficulty or not during the project development. On the other hand, Questions 4-6 are related to the Professor's performance; answers to these questions are based on the student's subjective judgment. Students frequently provide positive answers to these questions when they feel the Professor shows availability to clearly explain doubts about the content and the project, allowing them to obtain high scores during evaluations. Question 6 provides a general perspective about the student's motivation during the course, and his appreciation of the Professor's performance.

\section{Results}

First, let us show the scores that the students obtained in the theoretical modules. Figure 1 shows the scores of the modules of both groups. The Semestre i group obtained a higher score in the exam (about Module 1: Introduction to Mechanisms); however, the average score was the same for both groups in the synthesis and analysis exercises. The complementary data shown in the figure, such as median, percentiles, and outliers, provide confidence to consider average values for the analysis and the discussion. The same data are included in Figures 6 and 7. 


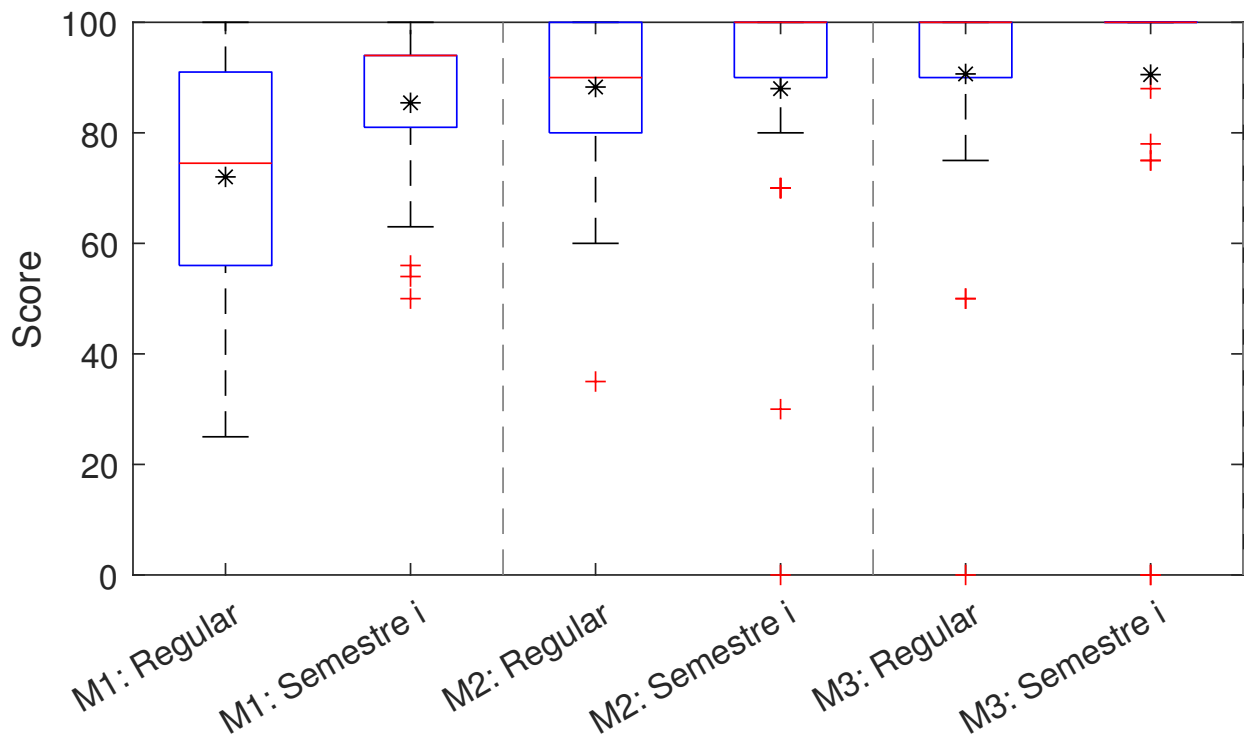

Figure 1. Evaluation of the theoretical modules. There were three evaluated activities: basic concepts exam, synthesis exercises, and analysis exercises. Average scores (marked as *) in the Regular group are 72, 88 and 91 for the corresponding activities. Average scores in the Semestre i group are 85, 88 and 91 for the corresponding activities. The central mark is the median, the top and bottom edges of the box indicate 25th and 75th percentiles, and the values within the whiskers do not consider outliers (outliers marked as + ).

Evaluation of the competencies 1.2 and 3.1 provided similar results in both groups. In order to ensure that students develop the competencies, students had the opportunity to receive feedback from the Professor during the activities development and, thus, to correct their works. Consequently, all the students in both groups developed both competencies.

In detail, competency 1.2 was evaluated through an activity in which each student must design a four-bar mechanism that lifts a box of dimension $30 \mathrm{~cm} \times 15 \mathrm{~cm}$ above $30 \mathrm{~cm}$ from the ground and rotates the box $90^{\circ}$ in the same movement. Later, students manufactured the four bars with steel bars according to the designed dimensions. Moreover, they improved a couple of joints by manufacturing fork and support extension joints. Figure 2 shows some images extracted from a report of this activity. This activity was developed in the campus facilities, where students have constant feedback from the Professor; thus, they have the opportunity to check and correct their works. The average score for the competency 1.2 for the Regular group was 91. Similarly, the average score for the Semestre i group was 97.

Competency 3.1 was evaluated through CAD drawings. Each student delivered a standardized manufacturing drawing of one component of his team project; moreover, the student also delivered an assembly drawing describing a sub-assembly of the prototype. Figure 3 shows an example of drawings made by one student. Since students had the opportunity to correct their drawings after receiving feedback from the Professor, all students of both groups achieved this competency.

Figures 4 and 5 show the best projects developed by the Semestre i group and the Regular group, respectively. It is worth noting that in Semestre $i$ all the teams developed a scissor lift, but with different features in its design and operation. 

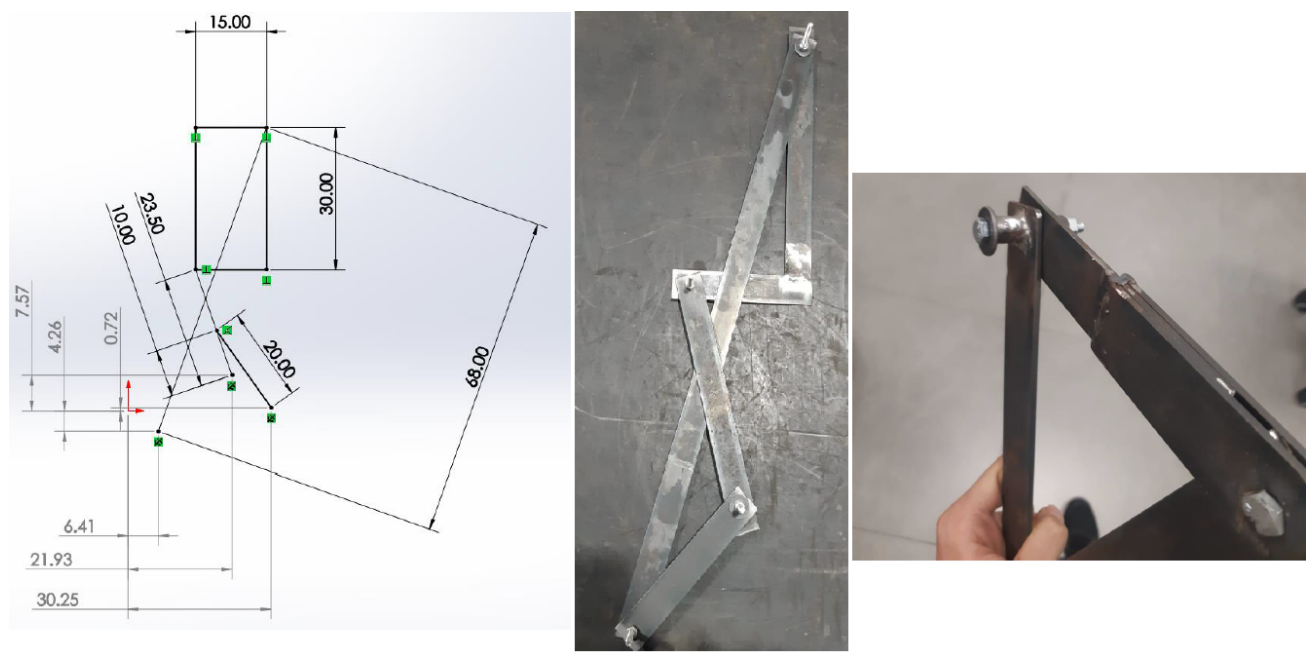

Figure 2. Images from a report of the activity of competency 1.2. Each student was required to synthesize and manufacture a four-bar mechanism to translate and rotate a box of certain dimensions. The image on the left shows the synthesized mechanism with the box in vertical position, the image in the middle shows a preliminary prototype of the mechanism, in which the four bars are manufactured with steel bars, and the image on the right shows an improvement of rotary joints, based on extensions and fork constructions.

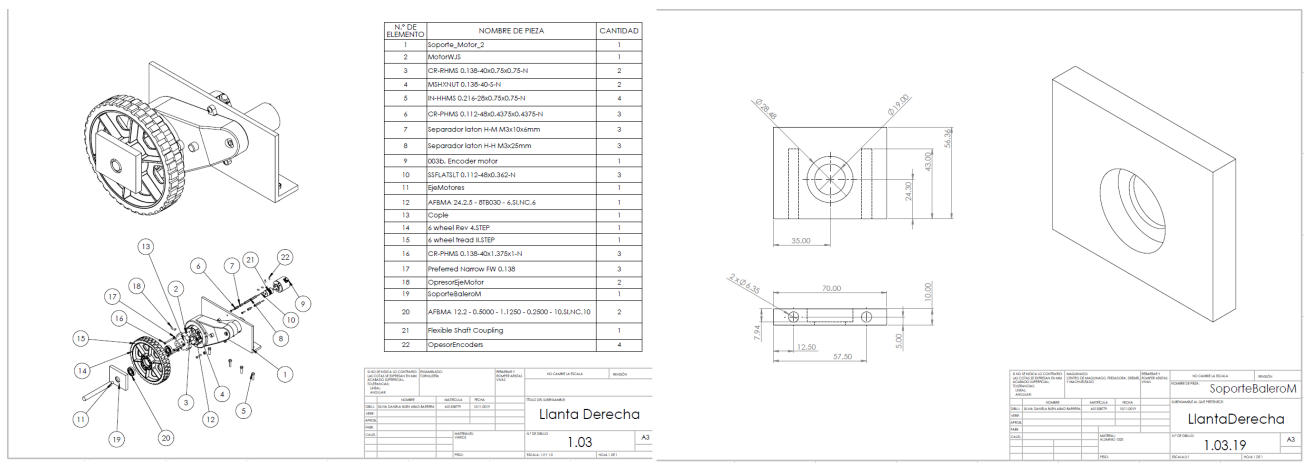

Figure 3. Images from a report of the activity of competency 3.1. Each student was required to perform a standardized assembly drawing and a component manufacture drawing.

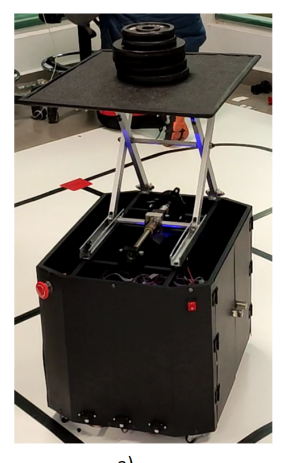

a)

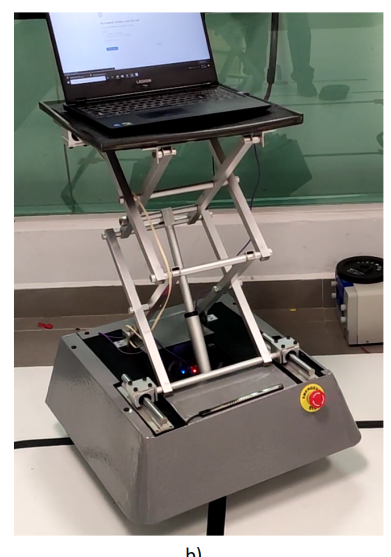

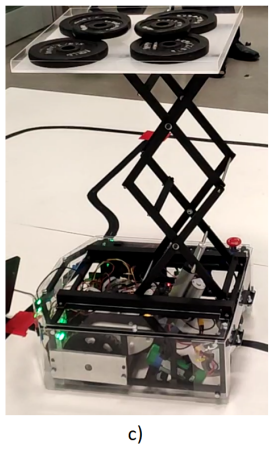

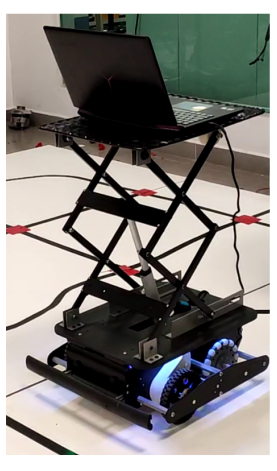

d)

Figure 4. Four prototypes developed in the Semestre i group. In all the cases, the developed mechanism consisted of a scissor lift with either a single stage (a) or a double stage (b-d). The mechanisms were actuated by a linear actuator $(\mathbf{b}-\mathbf{d})$ or a power screw $(\mathbf{a})$. Links were manufactured in aluminum, rotation joints were implemented with regular screws or round bars, and linear joints were implemented with grooved profiles/screws (a,d), commercial linear guides/bearings (b), and manufactured rail/wheels (c). 


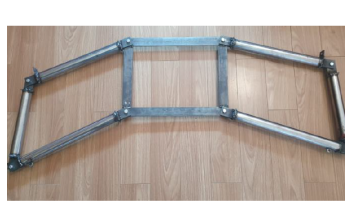

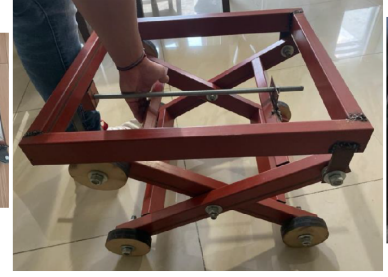

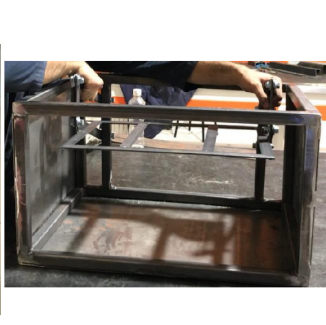

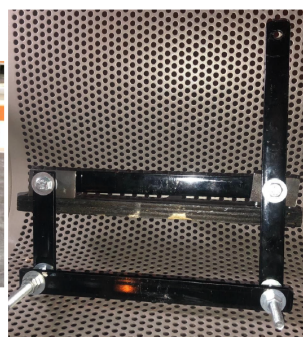

Figure 5. The best four prototypes developed in the Regular group. (a) Suspension prototype for a retail pushcart, (b) workshop table with a lift mechanism, (c) grill with a mechanism to select between two levels, (d) wiper washer mechanism. In these cases, links were manufactured with steel, and rotation joints were implemented with regular screws.

Figure 6 shows the results of the projects evaluation. As described in Section 2.3, for comparison purposes, the projects of both groups were evaluated by a team of three professors of the Mechanical and Mechatronics Department, considering seven aspects. Notoriously, the projects of the Semestre i group fulfilled all the aspects. On the other hand, the projects of the Regular group were deficient in almost all the aspects, excepting the third one: correct position analysis. In detail, regarding the first aspect, the students of the Regular group were not able to clearly establish the requirements in motion and force; there were a couple of cases in which those requirements were established, but no analysis was conducted to guarantee such requirements. Regarding the second aspect, the materials used in the prototype were not reported/justified in several projects of the Regular group. Some teams of the Regular group did not perform a force/torque analysis. Regarding the fifth and sixth aspects, the quality of the manufactured parts and the assembling was poor in half of the projects of the Regular group. Moreover, the difficulty of the designed and manufactured prototypes was far different between the Semestre $i$ and the Regular group. It can be noticed in Figure 5 that projects of the Regular group were incomplete in terms of including all the parts for their performance (e.g., Figure 5a,d); in some cases, mechanisms lack proper structure, joints were not completed or poorly implemented, etc.

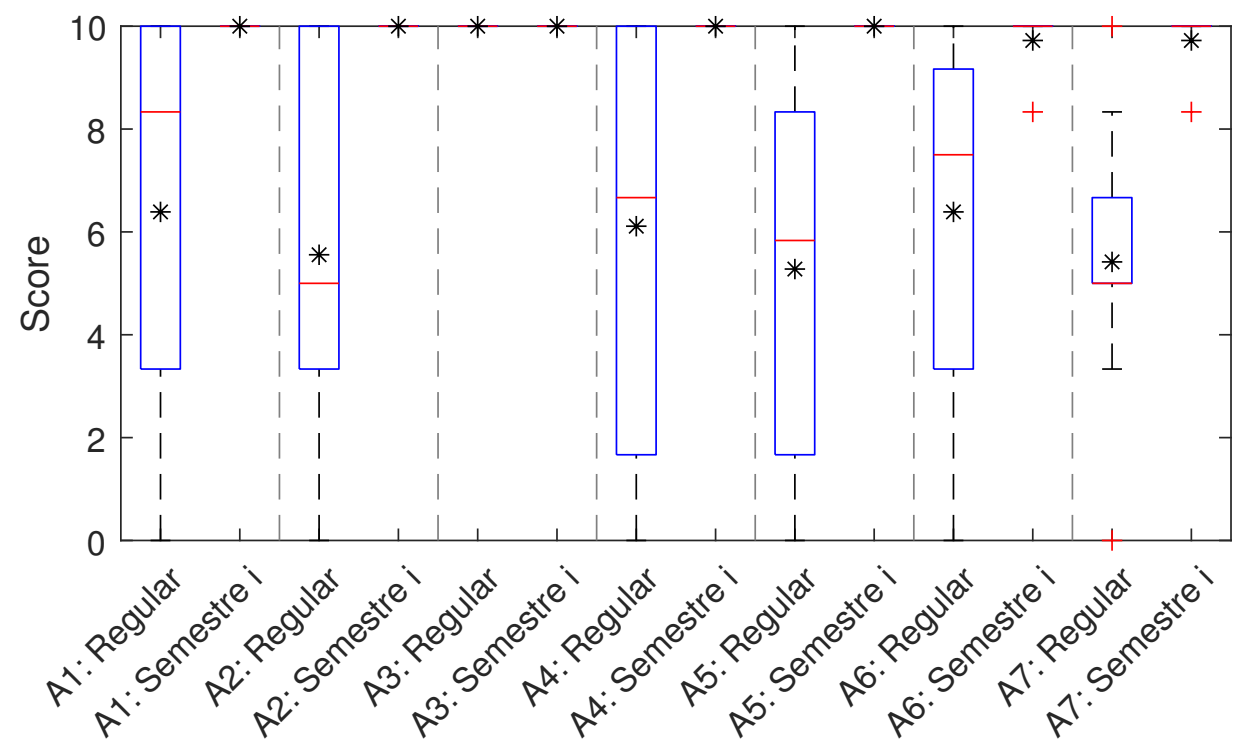

Figure 6. Average scores of the project aspects described in Section 2.3. Average scores (marked as *) in the Regular group are $6.38,5.55,10.0,6.11,5.27,6.38$ and 5.41 for the corresponding aspects. Average scores in the Semestre i group are 10.0, 10.0, 10.0, 10.0, 10.0, 9.72 and 9.72 for the corresponding aspects. The central mark is the median, the top and bottom edges of the box indicate 25th and 75th percentiles, and the values within the whiskers do not consider outliers (outliers marked as + ). 
Regarding students' perception, Figure 7 shows the scores obtained from the survey of student opinion (ECOA) of the Regular and Semestre i groups. The survey was answered by 30 students from the Semestre i group and 32 students from the Regular group. It can be observed that the students' overall appreciation was better in Semestre i compared to the Regular group. In fact, the score of the Semestre i group was higher in every question. In particular, the answer to Question 6, Would you recommend another student to take this course with this Professor, was 1 point higher (12\% higher) in the group of Semestre i, i.e., the general perception about the Professor's performance was better when the project was developed in the Semestre i format.

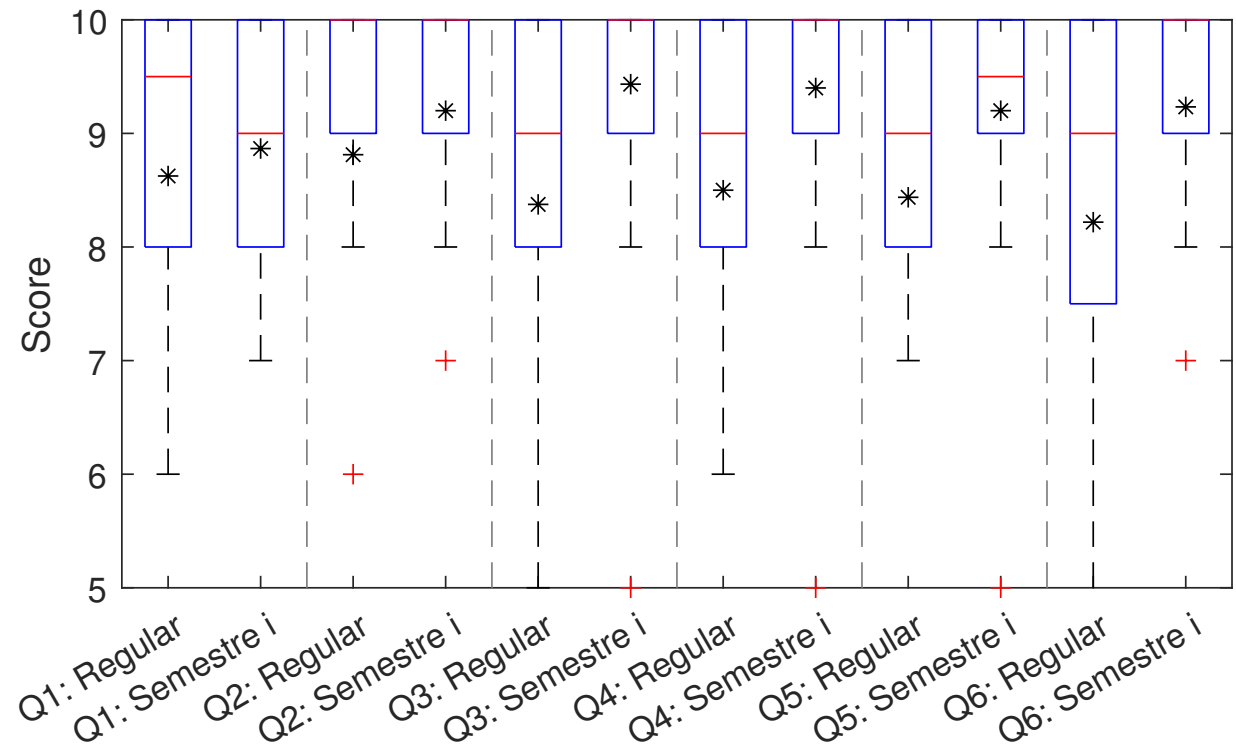

Figure 7. Average scores (marked as *) of the Survey of alumni opinion for both groups. Average scores in the Regular group are 8.63, 8.81, 8.38, 8.5, 8.44 and 8.22 for the corresponding questions. Average scores in the Semestre i group are 8.87, 9.2, 9.43, 9.4, 9.2 and 9.23 for the corresponding questions. The central mark is the median, the top and bottom edges of the box indicate 25 th and 75th percentiles, and the values within the whiskers do not consider outliers (outliers marked as + ).

\section{Discussion}

The results obtained by both groups in the theoretical modules were similar, i.e., the Semestre i format did not help to improve the learning of theoretical contents. This result is counter-intuitive. In fact, it is commonly said that the competency-based model improves the motivation of students for learning theoretical concepts by working on their applications. Nevertheless, in our setting, both groups obtained similar results; in fact, regarding synthesis and analysis of mechanisms, the scores were identical.

The main difference between the Semestre i group and the Regular group was found in the projects' development. All the projects developed in the Semestre i accomplished all the required aspects, including a good quality manufacture and assembly, a correct mechanism analysis, and a complete report. On the contrary, the prototypes developed by the Regular group exhibited significantly lower quality, while the performed analyses were incomplete in many cases. We argue that the difference in the projects development was a result of the projects setting and different motivation levels. Let us explain this argument in detail.

Regarding the first evaluated project aspect, the fulfillment of the requirements, the scores difference is a direct consequence of the projects setting: in Semestre i, the problem with its requirements were defined in detail by the team of professors, while in the Regular course, the students did not succeed in properly defining the problem and the requirements, which made the students uncertain of the project expectations. The low scores obtained by the Regular group teams in the last three evaluated project aspects, regarding the prototype 
quality, denote that these students did not spend enough time for manufacturing and assembling the prototype, perhaps because they were performing different small projects for other subjects during the term. These teams also obtained low scores in aspects 2 and 4 (materials and force/torque analysis, respectively). However, the good results obtained in the modules and the activities to evaluate competencies 1.2 and 3.1 imply that all the students in both groups had all the required knowledge and skills to develop these aspects. On the other hand, Semestre i students were highly motivated to develop a good project due to the following reasons: (1) the project concerns a real problem proposed by a company, (2) the project and its requirements are defined in detail by the professors and the trainer partner, (3) students focus on one project during the whole term, (4) a negative evaluation in the project/prototype would affect the evaluation of all the subjects in the term. The first reason has been already explored by Moreira et al. [42]; they evaluated the impact on the motivation of the students depending on the theme of the project developed using PBL in a similar context to the one presented here. They used a survey to measure this impact. Students responded that they were highly motivated if the theme was real and had a relevant impact on today's problems. For example, they ranked higher motivation for a project concerning biodiesel and lower motivation for a project related to space tourism. At the time of the study, space tourism was just a proposal, meanwhile using biodiesel was a relevant and current topic in the environment where the study was applied. This result relates to the results presented here as they suggest a similar conclusion. The motivation highly depends on the relevance of the project in a real-world problem. Different approaches were used to achieve this conclusion. Moreira et al. used a survey instrument. Here, the quality of the final prototype of the project is measured. With the quality of the prototype and the observed competencies developed, we draw the conclusion that students dealing with a real-world problem are highly motivated and this allows them to develop the related competencies.

It is clear that Semestre i students give more value to the experience in the project development than students in the Regular group. In fact, the largest differences in the survey of the students were encountered in the last four questions, regarding the Professor's performance and the general appreciation of the course. It is counter-intuitive that students of both groups almost agree in their perception of the relevance of the course contents and the level of intellectual challenge (Questions 1 and 2, Figure 5), which are the questions naturally associated with the projects. A similar conclusion is supported by Alves et al. [43]. They reported the perception of PBL in a semester project of students majoring in a similar major to the ones discussed here (Industrial Engineering). They applied a survey to quantify the perception of the students towards PBL. One of the main findings in their research is that students consider that PBL in a semester project helps to develop transversal competencies such as oral and written communication due to the teamwork required to work on the project. They also recognize that final grades of the course work evaluated were higher compared with not using PBL in the same courses. Here is presented one extra conclusion to the one presented by these authors; the appreciation of PBL in a real-world project. It seems that students develop a better appreciation of the Professor's work when he is helping them to find solutions to a real-world project rather than an academic project. Different authors $[42,44,45]$ reported results that complement the ones presented here regarding the perception of the lecturers in the process of competency development using PBL and the learning experience. The context of these studies is quite similar to the one investigated here regarding the engineering discipline and project developed. These works used a questionnaire to measure the perception of using PBL. Two results reported are worth mentioning. Lecturers have the general perception that PBL enhances the development of competencies and the workload is increased for the teachers to develop projects using the methodology. During this investigation, the perception of the teachers involved with the project agrees with the increase of the workload. However, one of the main challenges that the teachers involved in this investigation find is related to the project to be developed. The project must fulfill all the competencies declared to be developed in the specific course. This 
represents a huge challenge as some courses have competencies that might be not related. It makes it difficult to design a project partnered with industry or external organizations that complies with all the competencies declared. The recommendation is that during the design of the project, one must first acknowledge and recognize the competencies to be developed, and then design the project. It is a common practice to have an attractive project proposed by an external institution and then try to fit all the competencies in this project giving priority to the project rather than the competencies.

It is important to point out the selection of the students that took the Semestre $i$ and the Regular course. Students were not selected based on a specific population group rather than the major, as mentioned in Section 2.3. This limitation does not allow us to make further conclusions about other secondary factors that can impact the results, e.g., gender, age, background, or race. Nevertheless, the results provide direction towards the impact on developing competencies using PBL in a multidisciplinary environments as the main weight in the study. Further factors, such as those mentioned above, need to be investigated in more detail. The survey used to measure the satisfaction of the students towards the course is defined and designed by the institution. This instrument might bound the scope of the study for groups in a different context or educational system. Besides these limitations, the article provides semi-empirical evidence that supports the use of PBL combined with multidisciplinary projects as a good trend to be applied by educational institutions that are migrating their educational model towards competency development. The scope of this investigation applies to STEM programs at undergraduate and graduate levels that aim to develop technical competencies.

As a final comment, we would like to emphasize that the Semestre i project also helped students to develop competencies that were not considered during the Semestre i design, but are defined as competencies of the Mechatronics degree program in the Tec21 model. For instance, CC1.2 Application of mechanical technologies considering given requirements, CC1.3 Methodological selection of components, CC1.4 Analysis of interaction between different technological components (electrical, electronic, mechanical), CC2.2 Application of methodologies and tools in the design of mechatronic systems, and CC4.1 Documentation research of technical systems, among others. Further research is needed to evaluate the development level of these competencies.

In this work, we have compared the results of the students learning two different formats for a mechanism analysis and synthesis course taught in a mechanical/mechatronics program. There were three main findings:

1. The Semestre i format, focused on competency-based learning, did not help to improve the learning of theoretical contents. On the other hand, practical skills were significantly developed during the project development.

2. There are four features of Semestre i projects that are not present in the Regular course projects: (1) the project concerns a real problem proposed by a company, (2) the project and its requirements are defined in detail by the professors and the trainer partner, (3) students focus on one project during the whole term, (4) a negative evaluation of the project/prototype would affect the evaluation of all the subjects in the term. These features improve the students' motivation, which results in a significantly better project quality and the development of practical skills.

3. Students exhibit a better appreciation of the Professor's work when he is helping them to find solutions to a real-world project rather than an academic project.

Author Contributions: C.R.V. conducted the experiment and reviewed the competencies development, M.N.G. reviewed the competencies development, and A.G.-C. reviewed the competencies development and is the correspondent author. All the authors participated equally in the preparation of the manuscript, the discussion, and the results presented. All authors have read and agreed to the published version of the manuscript.

Funding: This research received no external funding. 
Institutional Review Board Statement: Not applicable.

Informed Consent Statement: Not applicable.

Data Availability Statement: The data presented in this study is available upon reasonable request to the corresponding author.

Acknowledgments: The authors would like to acknowledge the financial support of Writing Lab, Institute for the Future of Education, Tecnologico de Monterrey, Mexico, in the production of this work.

Conflicts of Interest: The authors declare no conflict of interest.

\section{References}

1. Ceccarelli, M. Mechanism Schemes in Teaching: A Historical Overview. J. Mech. Des. 1998, 120, 533-541. [CrossRef]

2. Evgrafov, A.; Khisamov, A.; Egorova, O. Experience of Modernization of the Curriculum TMM in St. Petersburg State Polytechnical University. In New Trends in Educational Activity in the Field of Mechanism and Machine Theory; García-Prada, J.C., Castejón, C., Eds.; Springer International Publishing: Cham, Switzerland, 2014; pp. 239-247.

3. Foix, S.C.; Nebot, L.J.; Pàmies-Vilà, R.; Calderón, P.C. Evolution of the Supervised Work in Machine and Mechanism Theory at ETSEIB. In New Trends in Educational Activity in the Field of Mechanism and Machine Theory; García-Prada, J.C., Castejón, C., Eds.; Springer International Publishing: Cham, Switzerland, 2014; pp. 303-310.

4. Cheng, H.H. Pedagogically effective programming environment for teaching mechanism design. Comput. Appl. Eng. Educ. 1994, 2, 23-39. [CrossRef]

5. Campbell, M.; Cheng, H.H. Teaching computer-aided mechanism design and analysis using a high-level mechanism toolkit. Comput. Appl. Eng. Educ. 2007, 15, 277-288. [CrossRef]

6. Cheng, H.H.; Campbell, M. Effective Teaching of Computer Integrated Mechanism Analysis and Design. In Proceedings of the 29th Mechanisms and Robotics Conference, Parts A and B and International Design Engineering Technical Conferences and Computers and Information in Engineering Conference, Long Beach, CA, USA, 24-28 September 2005; Volume 7, pp. 927-938. [CrossRef]

7. Katwyk, K.V.; Cheng, H.H. XLINKAGE: A Web-Based Analysis and Simulation Tool for Planar Mechanical Systems. In Proceedings of the DETC'97, ASME Design Engineering Technical Conferences, Sacramento, CA, USA, 14-17 September 1997.

8. Galan-Marin, G.; Alonso-Sanchez, F.J.; Del Castillo-Granados, J.M. A methodology to learn designing optimal mechanisms for path generation. Comput. Appl. Eng. Educ. 2010, 18, 87-92. [CrossRef]

9. Iriarte, X.; Aginaga, J.; Ros, J. Teaching Mechanism and Machine Theory with GeoGebra. In New Trends in Educational Activity in the Field of Mechanism and Machine Theory; García-Prada, J.C., Castejón, C., Eds.; Springer International Publishing: Cham, Switzerland, 2014; pp. 211-219.

10. Kuzlyakina, V.V. Modern Means and Technologies of Training on Course Theory of Mechanisms and Machines. In New Trends in Educational Activity in the Field of Mechanism and Machine Theory; García-Prada, J.C., Castejón, C., Eds.; Springer International Publishing: Cham, Switzerland, 2014; pp. 83-92.

11. Urízar, M.; Altuzarra, O.; Diez, M.; Campa, F.J.; Macho, E. Kinematic Analysis of Planar Mechanisms by Means of Examples. In New Trends in Educational Activity in the Field of Mechanism and Machine Theory; García-Prada, J.C., Castejón, C., Eds.; Springer International Publishing: Cham, Switzerland, 2014; pp. 203-210.

12. Kurtenbach, S.; Prause, I.; Weigel, C.; Corves, B. Comparison of Geometry Software for the Analysis in Mechanism Theory. In New Trends in Educational Activity in the Field of Mechanism and Machine Theory; García-Prada, J.C., Castejón, C., Eds.; Springer International Publishing: Cham, Switzerland, 2014; pp. 193-201.

13. Barbero, B.R.; García, R.G. Strategic learning of simulation and functional analysis in the design and assembly of mechanisms with CAD on a professional Master's degree course. Comput. Applic. Eng. Educ. 2011, 19, 146-160. [CrossRef]

14. Corral Abad, E.; Gómez García, M.J.; Ruiz Blázquez, R.; Bustos-Caballero, A.; García-Prada, J.C. Using an Android App for Teaching Mechanism and Machine Theory. In New Trends in Educational Activity in the Field of Mechanism and Machine Theory; García-Prada, J., Castejón, C., Eds.; Springer International Publishing: Cham, Switzerland, 2019; pp. 103-110.

15. Kurtenbach, S.; Mannheim, T.; Hüsing, M.; Corves, B. Content and Realization of Education in Mechanism Theory at RWTH Aachen University. In New Trends in Educational Activity in the Field of Mechanism and Machine Theory; García-Prada, J.C., Castejón, C., Eds.; Springer International Publishing: Cham, Switzerland, 2014; pp. 39-46.

16. Tarabarin, V.B.; Tarabarina, Z.I.; Feygina, A.G. Virtual Laboratory Works on Theory of Mechanism and Machine. In New Trends in Educational Activity in the Field of Mechanism and Machine Theory; García-Prada, J.C., Castejón, C., Eds.; Springer International Publishing: Cham, Switzerland, 2014; pp. 171-180.

17. Martínez, J.L.S.; Carballeira, J. Enhancing Mechanism and Machine Science Learning by Creating Virtual Labs with ADAMS. In New Trends in Educational Activity in the Field of Mechanism and Machine Theory; García-Prada, J.C., Castejón, C., Eds.; Springer International Publishing: Cham, Switzerland, 2014; pp. 221-228.

18. Kuzlyakina, V.V. Integration Processes in Engineering Education. In New Trends in Educational Activity in the Field of Mechanism and Machine Theory; García-Prada, J.C., Castejón, C., Eds.; Springer International Publishing: Cham, Switzerland, $2014 ;$ pp. 47-55. 
19. García-Alonso, J.M.; Soriano, E.; García-Vicario, I.; Rubio, H. Service-Learning Projects Based on Dynamic Documentation in Engineering Colleges. In New Trends in Educational Activity in the Field of Mechanism and Machine Theory; García-Prada, J.C., Castejón, C., Eds.; Springer International Publishing: Cham, Switzerland, 2014; pp. 69-81.

20. Duma, V.F.; Schitea, A.; Tuef, M.; Cira, O.; Mnerie, C.; Hutiu, G.; Demian, D.; Kaposta, I. Optomechatronics Applications of the Theory of Mechanisms with Active Student Involvement in Research. In New Trends in Educational Activity in the Field of Mechanism and Machine Theory; García-Prada, J.C., Castejón, C., Eds.; Springer International Publishing: Cham, Switzerland, 2014; pp. 111-119.

21. del Rincón, A.F.; de Juan, A.; García, P.; Iglesias, M.; Viadero, F. Application of a Inter-University Competition on the Enhancement of Engineering Degrees. In New Trends in Educational Activity in the Field of Mechanism and Machine Theory; García-Prada, J.C., Castejón, C., Eds.; Springer International Publishing: Cham, Switzerland, 2014; pp. 259-266.

22. Esche, S.K. Project-Based Learning (PBL) in a course on mechanisms and machine dynamics. World Trans. Eng. Technol. Educ. 2002, 1, 201-204.

23. Krajcik, J.S.; Blumenfeld, P.C. Project-Based Learning. In The Cambridge Handbook of the Learning Sciences; Cambridge University Press: Cambridge, UK, 2005; pp. 317-334.

24. Solomon, G. Project-based learning: A primer. Technol. Learn. Dayt. 2003, 23, 20.

25. Barron, B.J.; Schwartz, D.L.; Vye, N.J.; Moore, A.; Petrosino, A.; Zech, L.; Bransford, J.D. Doing with understanding: Lessons from research on problem-and project-based learning. J. Learn. Sci. 1998, 7, 271-311.

26. Efstratia, D. Experiential Education through Project Based Learning. Procedia Soc. Behav. Sci. 2014, 152, 1256-1260. [CrossRef]

27. de Graaff, E.; Kolmos, A. History of Problem-Based and Project-Based Learning; Brill I Sense: Leiden, The Netherlands, 2007; pp. 1-8. [CrossRef]

28. De Graaff, E.; Kolmos, A. Management of Change: Implementation of Problem-Based and Project-Based Learning in Engineering; Brill I Sense: Rotterdam, The Netherlands, 2007.

29. Weatherby, K. Project-Based Learning around the World, Part 2. Learn. Lead. Technol. 2007, 34, $26-29$.

30. Lehmann, M.; Christensen, P.; Du, X.; Thrane, M. Problem-oriented and project-based learning (POPBL) as an innovative learning strategy for sustainable development in engineering education. Eur. J. Eng. Educ. 2008, 33, 283-295. [CrossRef]

31. Brundiers, K.; Wiek, A. Do we teach what we preach? An international comparison of problem-and project-based learning courses in sustainability. Sustainability 2013, 5, 1725-1746. [CrossRef]

32. Wiek, A.; Xiong, A.; Brundiers, K.; Van Der Leeuw, S. Integrating problem-and project-based learning into sustainability programs: A case study on the School of Sustainability at Arizona State University. Int. J. Sustain. High. Educ. 2014, 15, 431-449. [CrossRef]

33. Membrillo-Hernández, J.; Muñoz-Soto, R.B.; Rodríguez-Sánchez, Á.C.; Díaz-Quiñonez, J.A.; Villegas, P.V.; Castillo-Reyna, J.; Ramírez-Medrano, A. Student Engagement Outside the Classroom: Analysis of a Challenge-Based Learning Strategy in Biotechnology Engineering. In Proceedings of the 2019 IEEE Global Engineering Education Conference (EDUCON), Dubai, United Arab Emirates, 8-11 April 2019; pp. 617-621. [CrossRef]

34. Reyna-González, J.M.; Ramírez-Medrano, A.; Membrillo-Hernández, J. Challenge Based Learning in the 4IR: Results on the Application of the Tec21 Educational Model in an Energetic Efficiency Improvement to a Rustic Industry. In The Impact of the 4th Industrial Revolution on Engineering Education; Auer, M.E., Hortsch, H., Sethakul, P., Eds.; Springer International Publishing: Cham, Switzerland, 2020; pp. 760-769.

35. Grasha, A. Teaching with Style: A Practical Guide to Enhancing Learning by Understanding Teaching and Learning Styles; Curriculum for Change Series; Alliance Publishers: Pittsburgh, PA, USA, 1996.

36. Burke, J. Competency Based Education and Training; Falmer Press: London, UK, 1989.

37. Harris, R.; Guthrie, H.; Hobart, B.; Lundberg, D. Competency-Based Education and Training: Between a Rock and a Whirlpool; Macmillan Education: South Melbourne, Australia, 1995.

38. Johnstone, S.M.; Soares, L. Principles for Developing Competency-Based Education Programs. Change Mag. High. Learn. 2014, 46, 12-19. [CrossRef]

39. Guajardo-Cuéllar, A. Molecular Dynamics Simulations as a Competence Developer for Materials Science. In Proceedings of the 2020 International Conference on Computation, Automation and Knowledge Management (ICCAKM), Dubai, United Arab Emirates, 9-10 January 2020; pp. 328-331. [CrossRef]

40. Guajardo-Cuéllar, A.; Cárdenas, D.; Lepe, M. Fabrication of a Boomerang Using Computational Tools to Develop Engineering Competences. Int. J. Mech. Eng. Robot. Res. 2020, 9, 1406-1410. [CrossRef]

41. Norton, R. Design of Machinery: An Introduction to the Synthesis and Analysis of Mechanisms and Machines; McGraw-Hill Series in Mechanical Engineering; McGraw-Hill Higher Education: New York, NY, USA, 2004.

42. Moreira, F.; Mesquita, D.; Hattum-Janssen, N.V. The Importance of the Project Theme in Project-Based Learning: A Study of Student and Teacher Perceptions. 2011. Available online: https://repositorium.sdum.uminho.pt/handle/1822/14952 (accessed on 8 February 2022).

43. Alves, A.C.; Moreira, F.; Lima, R.; Sousa, R.; Dinis-Carvalho, J.; Mesquita, D.; Fernandes, S.; van Hattum-Janssen, N. Project Based Learning in First Year, First Semester of Industrial Engineering and Management: Some Results. In Proceedings of the Education and Globalization, General Topics, ASME International Mechanical Engineering Congress and Exposition, Houston, TX, USA, 9-15 November 2012; Volume 5, pp. 111-120. [CrossRef] 
44. Moreira, F.; Rodrigues, C.; Alves, A.C.; Malheiro, M.T.; Brito, I.; Carvalho, M.A. Lecturers' Perceptions of a Semester-Wide Interdisciplinary PBL in a Master's Degree Program in Industrial Engineering and Management. In Proceedings of the Education and Globalization, ASME International Mechanical Engineering Congress and Exposition, Tampa, FL, USA, 3-9 November 2017; Volume 5. [CrossRef]

45. Alves, A.C.; Sousa, R.M.; Fernandes, S.; Cardoso, E.; Carvalho, M.A.; Figueiredo, J.; Pereira, R.M. Teacher's experiences in PBL: Implications for practice. Eur. J. Eng. Educ. 2016, 41, 123-141. [CrossRef] 